\title{
HUBUNGAN KECANDUAN BERMAIN GAME ONLINE TERHADAP INTERAKSI SOSIAL PADA REMAJA
}

\author{
Eka Arista Anjasari ${ }^{\S 1}$, I Gusti Ayu Made Srinadi ${ }^{2}$, Desak Putu Eka Nilakusmawati ${ }^{3}$ \\ ${ }^{1}$ Program Studi Matematika, Fakultas MIPA - Universitas Udayana [Email: aiaiairista@gmail.com] \\ ${ }^{2}$ Program Studi Matematika, Fakultas MIPA - Universitas Udayana [Email: srinadi@ unud.ac.id] \\ ${ }^{3}$ Program Studi Matematika, Fakultas MIPA - Universitas Udayana [Email: nilakusmawati@unud.ac.id] \\ ${ }^{\S}$ Corresponding Author
}

\begin{abstract}
Social interaction in adolescents in the modern era is influenced by several factors in life, one of which is addiction to playing online games. This study aims to determine the relationship between factors addicted to playing online games on social interaction in teenagers. The data used in this study are primary data which are the results of questionnaires. The data processing technique used in this study is canonical correlation analysis. The sample in this study were adolescents aged 13 to 21 years and living in the city of Denpasar, with a total sample of 150 adolescents. The results showed that the addiction factor playing online games had a significant effect of 0.0000019 on social interaction in adolescents with a close relationship of 0.8058964.
\end{abstract}

Keywords: Addiction to Playing Online Games, Canonical Correlation Analysis, Online Games, Social Interaction.

\section{PENDAhULUAN}

Manusia memiliki naluri untuk saling berhubungan dengan sesamanya sehingga menghasilkan sebuah pola pergaulan yang dinamakan pola interaksi sosial (Kusnadi dan Iskandar, 2017). Interaksi sosial merupakan suatu hubungan sosial yang bersifat dinamis, menyangkut antar individu, antar kelompok manusia, maupun antar individu dengan kelompok manusia (Soekanto , 2012).

Menurut Dewi (2014), ditinjau dari sudut perkembangan manusia, kebutuhan untuk berinteraksi sosial paling menonjol terjadi pada masa remaja. Interaksi sosial bagi remaja penting untuk proses penyesuaian diri dalam kehidupan sehari-hari remaja agar memperoleh hubungan timbal balik yang baik antar remaja maupun manusia lainnya. Menurut Kartini (2007), beberapa batasan usia remaja terdiri dari masa remaja awal (12 -15 tahun), masa remaja pertengahan (15-18 tahun), dan masa remaja akhir (18-21 tahun). Soekanto (2012) menyebutkan bahwa ada empat bentuk interaksi sosial yaitu kerjasama, persaingan, pertentangan, dan akomodasi.

Dampak teknologi bagi remaja sangat besar terutama pada kegiatan bermain remaja.
Sebelum adanya perkembangan teknologi remaja melakukan permainan dilapangan, akan tetapi semakin pesatnya teknologi saat ini membuat remaja beralih ke permainan elektronik berupa game online. Game online sangat menyenangkan dan menghibur namun memiliki sifat yang membuat remaja kecanduan. Banyak remaja laki-laki yang memiliki waktu luang dan hobi dalam bermain game membuat mereka lebih banyak menghabiskan waktunya bermain game online baik di rumah maupun di sekolah hingga mereka kecanduan bermain dan berdampak pada kesulitan berinteraksi sosial di lingkungan yang nyata. Griffiths dan Davies (2005) mengatakan bahwa ada enam aspek yang membuat remaja kecanduan game online yaitu salience, mood modification, tolerance, withdrawal symptoms, conflict, dan relapss.

Remaja yang sudah kecanduan bermain game online memiliki kehidupan yang monoton dalam kesehariannya akibatnya interaksi sosial yang dilakukan remaja menjadi sangat kurang di lingkungan sekitar. Kurangnya keterampilan dalam berinteraksi sosial membuat remaja merasa tidak nyaman untuk berbaur dengan teman-temannya. Dalam pola pikir remaja yang masih labil dan tidak percaya diri, remaja 
membutuhkan perhatian dan empati dari lingkungan terkecil seperti keluarga untuk membentuk pola interaksi remaja secara baik.

Penelitian sebelumnya oleh Ulfa (2017) yang melakukan penelitian di Mabes Game Center, Pekanbaru, menyimpulkan bahwa hubungan kecanduan bermain game online berpengaruh secara signifikan terhadap perilaku remaja. Sementara penelitian oleh Dewi (2014) melakukan penelitian di game center Aurora, menyimpulkan bahwa adanya hubungan negatif yang signifikan di antara intensitas bermain game online terhadap interaksi sosial.

Berdasarkan penelitian tersebut, maka peneliti mencoba untuk melakukan penelitian mengenai "hubungan kecanduan bermain game online terhadap interaksi sosial pada remaja".

Tujuan penelitian ini adalah mengetahui terdapatnya hubungan kecanduan bermain game online terhadap interaksi sosial pada remaja dengan memfokuskan penelitian ini di wilayah Kota Denpasar.

\section{METODE PENELITIAN}

Data yang digunakan dalam penelitian ini merupakan data primer diperoleh dari responden secara langsung yaitu para remaja yang bermain game online di Kota Denpasar dengan menyebarkan kuesioner. Sampel dalam penelitian ini adalah para remaja yang berusia 13 sampai 21 tahun. Teknik pengambilan sampel yang digunakan dalam penelitian ini adalah Purposive sampling. Purposive sampling digunakan jika peneliti mempunyai pertimbangan-pertimbangan tertentu di dalam pengambilan sampel untuk tujuan tertentu (Riduwan, 2004). Jumlah sampel yang digunakan adalah 150 responden remaja yang tersebar di wilayah Kota Denpasar.

Variabel yang digunakan dalam penelitian ini adalah interaksi sosial (Y) meliputi Kerjasama $\left(\mathrm{Y}_{1}\right)$, Persaingan $\left(\mathrm{Y}_{2}\right)$, Pertentangan $\left(\mathrm{Y}_{3}\right)$, Akomodasi $\left(\mathrm{Y}_{4}\right)$ dan Kecanduan Game Online (X) meliputi Salience $\left(\mathrm{X}_{1}\right)$, Mood Modification $\left(\mathrm{X}_{2}\right)$, Tolerance $\left(\mathrm{X}_{3}\right)$, Withdrawal Symptoms $\left(\mathrm{X}_{4}\right)$, Conflict $\left(\mathrm{X}_{5}\right)$, Relapss $\left(\mathrm{X}_{6}\right)$.

Pengujian data hasil penyebaran kuesioner diolah dengan menggunakan uji validitas dan reliabilitas terhadap data yang diperoleh dengan program SPSS, kemudian dianalisis menggunakan metode Analisis Korelasi Kanonik untuk mengetahui terdapatnya hubungan kecanduan bermain game online terhadap interaksi sosial serta hubungannya dengan masing-masing indikator penyusun dengan menggunakan Program STATISTICA versi 12 .

\section{HASIL DAN PEMBAHASAN}

\subsection{Deskripsi Data}

Pada penelitian ini karakteristik responden penelitian yang diambil adalah remaja laki-laki maupun perempuan dengan rentang usia 13 sampai 21 tahun yang gemar bermain game online, para remaja tersebut telah bermain game online minimal satu tahun serta masih aktif dalam bermain game dan minimal lima jam bermain game online dalam sehari.

\subsection{Uji Validitas dan Reliabilitas Kuesioner}

Uji validitas digunakan untuk menguji valid tidaknya jawaban kuesioner yang telah diberikan oleh responden, sementara uji reliabilitas digunakan untuk mengetahui reliabelnya instrument atau alat pengumpul data yang digunakan. Dalam hal ini, tahap awal untuk menguji validitas dan reliabilitas kuesioner maka di lakukan penyebaran kuesioner secara acak kepada 20 responden remaja yang tersebar di wilayah Kota Denpasar. Pengujian 20 responden ini dilakukan untuk memudahkan peneliti menentukan valid dan reliabelnya data. Dari hasil data penyebaran kuesioner tersebut kemudian diolah dengan menggunakan uji validitas dan reliabilitas pada program SPSS Statistics 22.

Cara melakukan uji validitas yaitu dengan membandingkan nilai $t_{\text {hitung }}$ dengan nilai $t_{\text {tabel }}$. Apabila data hasil kuesioner memiliki nilai $t_{\text {hitung }}$ lebih besar dari nilai $t_{\text {tabel }}$, maka data tersebut dikatakan valid, dan sebaliknya apabila data hasil kuesioner memiliki nilai $t_{\text {hitung }}$ lebih kecil dari nilai $t_{\text {tabel }}$ maka di katakan tidak valid (Sugiyono, 2008).

Hasil uji validitas dari 29 item pertanyaan pada kuesioner didapatkan perbandingan nilai $\mathrm{t}_{\text {hitung }}$ lebih besar dari nilai $\mathrm{t}_{\text {tabel }}$ 1,734 dimana $\mathrm{n}=20$ dan derajat bebas $\mathrm{n}-2(\mathrm{db}=18)$. Hal ini dapat disimpulkan bahwa keseluruhan item pertanyaan bersifat valid.

Hasil analisis reliabilitas kuesioner dengan nilai $r$ Alpha Cronbach's sebesar 0,950 menunjukkan nilai lebih besar dari 0,6 sehingga kuesioner yang digunakan untuk penelitian bersifat reliabel. 


\subsection{Uji Signifikan Nilai Korelasi}

Langkah awal untuk melakukan uji signifikan korelasi kanonik adalah melihat korelasi antara faktor kecanduan game online terhadap interaksi sosial dapat dilihat pada Tabel 1.

Tabel 1. Uji Signifikan Nilai Korelasi Faktor Kecanduan Game Online terhadap Interaksi Sosial

\begin{tabular}{|l|c|c|}
\hline $\begin{array}{l}\text { Hubungan Faktor } \\
\text { dengan Interaksi } \\
\text { Sosial }\end{array}$ & $\begin{array}{c}\text { Nilai } \\
\text { Korelasi }\end{array}$ & P value \\
\hline $\begin{array}{l}\text { Kecanduan Game } \\
\text { Online }\end{array}$ & 0,8058964 & 0,0000019 \\
\hline
\end{tabular}

Uji signifikan analisis korelasi kanonik dilakukan dengan melihat perbandingan antara $\mathrm{P}_{\text {value }}$ dan nilai taraf nyata $(\alpha)$ sebesar 0,05 . Nilai dapat dikatakan signifikan jika $\mathrm{P}_{\text {value }}$ lebih kecil dari taraf nyata $(\alpha)$. Hasil uji signifikan tersebut menunjukkan bahwa terdapat hubungan yang signifikan antara faktor kecanduan game online terhadap interaksi sosial.

\subsection{Uji Signifikan Nilai Korelasi Antara Indikator Penyusun Kecanduan Bermain Game Online terhadap Interaksi Sosial}

Langkah selanjutnya yaitu melakukan uji antara masing-masing indikator penyusun faktor kecanduan bermain game online terhadap interaksi sosial. Hal ini dilakukan untuk mengetahui nilai korelasi kanonik yang memiliki hub ungan signifikan antara masingmasing indikator tersebut dapat dilihat pada Tabel 2 .

Hasil uji signifikan analisis korelasi kanonik tersebut menunjukkan bahwa hanya ada lima indikator dengan nilai korelasi yang signifikan terhadap interaksi sosial yaitu salience, mood modification, tolerance, withdrawal Symptoms, dan relapss. Dari semua indikator tersebut, indikator salience memiliki pengaruh paling besar dibandingkan dengan indikator-indikator lain terhadap interaksi sosial. Dan ada satu indikator yang tidak memiliki hubungan signifikan terhadap interaksi sosial yaitu conflict.

Tabel 2. Uji Signifikan Nilai Korelasi antara Indikator Penyusun faktor Kecanduan Game Online terhadap Interaksi Sosial

\begin{tabular}{|l|c|c|}
\hline $\begin{array}{l}\text { Hubungan antara } \\
\text { Indikator Penyusun } \\
\text { Kecanduan Game } \\
\text { Online terhadap } \\
\text { Interaksi Sosial }\end{array}$ & $\begin{array}{c}\text { Nilai } \\
\text { Korelasi }\end{array}$ & Pvalue \\
\hline Salience & 0,6144140 & 0,0001994 \\
\hline Mood Modification & 0,5777870 & 0,0000004 \\
\hline Tolerance & 0,5016082 & 0,0002321 \\
\hline $\begin{array}{l}\text { Withdrawal } \\
\text { Symptoms }\end{array}$ & 0,4117372 & 0,0080615 \\
\hline Conflict & 0,3954694 & 0,7646528 \\
\hline Relapss & 0,4405295 & 0,0067605 \\
\hline
\end{tabular}

\subsection{Uji Signifikan Nilai Korelasi Antara Indikator Penyusun Kecanduan Bermain Game Online terhadap Indikator Penyusun Interaksi Sosial}

Selanjutnya uji signifikan nilai korelasi antara masing-masing indikator yang di analisis adalah indicator- indikator penyusun kecanduan bermain game online terhadap indicatorindikator penyusun interaksi sosial. Pengujian ini dilakukan untuk melihat terdapatnya hubungan masing-masing indikator secara terpisah dapat dilihat pada Tabel 3.

Tabel 3. Uji Signifikan Nilai Korelasi Antara Indikator Penyusun Kecanduan Bermain Game Online terhadap Indikator Penyusun Interaksi Sosial

\begin{tabular}{|lll|c|c|}
\hline \multicolumn{2}{|c|}{ Hubungan antar Indikator } & Nilai Korelasi & Pvalue \\
\hline Salience & dengan & Kerjasama & $\mathbf{0 , 4 1 1 5 4 7 1}$ & $\mathbf{0 , 0 0 4 6 0 8 4}$ \\
\hline Mood Modification & dengan & Kerjasama & $\mathbf{0 , 3 7 9 0 8 1 8}$ & $\mathbf{0 , 0 0 0 1 3 9 0}$ \\
\hline Tolerance & dengan & Kerjasama & $\mathbf{0 , 3 5 5 5 0 2 8}$ & $\mathbf{0 , 0 0 0 1 4 1 7}$ \\
\hline Withdrawal Symptoms & dengan & Kerjasama & 0,2348254 & 0,0655059 \\
\hline Conflict & dengan & Kerjasama & 0,2132156 & 0,6641978 \\
\hline Relapss & dengan & Kerjasama & $\mathbf{0 , 2 4 5 9 3 5 7}$ & $\mathbf{0 , 0 3 0 5 6 1 4}$ \\
\hline Salience & dengan & Persaingan & 0,3395418 & 0,1824134 \\
\hline Mood Modification & dengan & Persaingan & $\mathbf{0 , 3 8 6 4 9 1 4}$ & $\mathbf{0 , 0 0 1 7 5 5 0}$ \\
\hline Tolerance & dengan & Persaingan & 0,2910830 & 0,0878797 \\
\hline
\end{tabular}


Tabel 3. Uji Signifikan Nilai Korelasi Antara Indikator Penyusun Kecanduan Bermain Game Online terhadap Indikator Penyusun Interaksi Sosial (lanjutan)

\begin{tabular}{|lll|l|l|}
\hline Withdrawal Symptoms & dengan & Persaingan & 0,2036914 & 0,3809535 \\
\hline Conflict & dengan & Persaingan & 0,1942150 & 0,9652615 \\
\hline Relapss & dengan & Persaingan & 0,2016124 & 0,4530908 \\
\hline Salience & dengan & Pertentangan & 0,3172398 & 0,0863251 \\
\hline Mood Modification & dengan & Pertentangan & $\mathbf{0 , 2 3 2 2 9 8 9}$ & $\mathbf{0 , 0 4 4 6 9 7 3}$ \\
\hline Tolerance & dengan & Pertentangan & $\mathbf{0 , 2 8 9 0 3 0 5}$ & $\mathbf{0 , 0 1 1 9 4 4 9}$ \\
\hline Withdrawal Symptoms & dengan & Pertentangan & $\mathbf{0 , 2 2 4 2 8 3 5}$ & $\mathbf{0 , 0 2 8 2 7 7 3}$ \\
\hline Conflict & dengan & Pertentangan & 0,3094634 & 0,0654484 \\
\hline Relapss & dengan & Pertentangan & $\mathbf{0 , 2 5 3 8 1 0 8}$ & $\mathbf{0 , 0 2 7 7 8 7 0}$ \\
\hline Salience & dengan & Akomodasi & $\mathbf{0 , 4 0 6 0 6 2 2}$ & $\mathbf{0 , 0 0 5 2 4 1 3}$ \\
\hline Mood Modification & dengan & Akomodasi & $\mathbf{0 , 3 3 9 5 5 1 4}$ & $\mathbf{0 , 0 0 1 0 3 6 2}$ \\
\hline Tolerance & dengan & Akomodasi & $\mathbf{0 , 3 7 0 2 8 8 1}$ & $\mathbf{0 , 0 0 0 2 3 3 2}$ \\
\hline Withdrawal Symptoms & dengan & Akomodasi & $\mathbf{0 , 3 7 0 7 6 5 7}$ & $\mathbf{0 , 0 0 0 1 6 5 0}$ \\
\hline Conflict & dengan & Akomodasi & 0,2819591 & 0,1683573 \\
\hline Relapss & dengan & Akomodasi & $\mathbf{0 , 3 1 4 2 9 3 9}$ & $\mathbf{0 , 0 0 4 2 4 0 0}$ \\
\hline
\end{tabular}

Hasil uji signifikan untuk nilai korelasi pada tabel 3 menunjukkan bahwa diantara dua puluh empat hubungan indikator penyusun kecanduan bermain game online terhadap indikator penyusun interaksi sosial terdapat empat belas nilai korelasi yang signifikan.

\subsection{Interpretasi Hasil Korelasi Kanonik}

Dari penjabaran hasil uji signifikan nilai korelasi kanonik kecanduan bermain game online terhadap interaksi sosial pada remaja dapat dilihat bahwa ada hubungan yang signifikan dan berpengaruh secara nyata terhadap interaksi sosial. Hal ini dapat dilihat dari nilai korelasi kecanduan bermain game online sebesar 0,8058964. Dimana remaja yang semakin kecanduan bermain game online akan berpengaruh terhadap penurunan interaksi sosialnya.

Dapat diketahui indikator-indikator penyusun kecanduan bermain game online antara lain adalah Salience, Mood Modification, Tolerance, Withdrawal Symptoms, Conflict, dan Relapss. Dari penjabaran hasil uji nilai signifikan korelasi antara indikator penyusun kecanduan bermain game online terhadap interaksi sosial dapat dilihat bahwa dari enam indikator, hanya lima indikator memiliki hubungan yang signifikan. Kelima indikator tersebut yaitu Salience, Mood Modification, Tolerance, Withdrawal Symptoms, dan Relapss. Hasil uji signifikan nilai korelasi dari kelima indikator menunjukkan bahwa Salience, Mood Modification, Tolerance, Withdrawal Symptoms, dan Relapss mempengaruhi interaksi sosial pada remaja.
Hasil uji signifikan nilai korelasi antara indikator Salience terhadap interaksi sosial adalah sebesar 0,6144140 dengan Pvalue 0,0001994. Hal ini menjelaskan bahwa indikator Salience berpengaruh secara nyata terhadap interaksi sosial. Dimana semakin tinggi remaja yang menunjukkan indikator salience dalam bermain game online, maka semakin tinggi pengaruhnya terhadap interaksi sosial. Dari hasil penelitian dapat dilihat bahwa para remaja menjadikan aktivitas bermain game sangat penting sehingga remaja selalu memikirkan game online sepanjang hari hasilnya remaja jarang berinteraksi sosial terhadap teman sebayanya.

Nilai korelasi antara indikator Mood Modification terhadap interaksi sosial memiliki hasil uji signifikan sebesar 0,5777870 dengan Pvalue 0,0000004. Sehingga indikator Mood Modification secara nyata berpengaruh terhadap interaksi sosial. Artinya kegiatan bermain game online bagi remaja mampu untuk mengasah kemampuan berbahasa seperti bahasa inggris sehingga remaja merasa lebih senang berinteraksi sosial lewat dunia maya dibandingkan berinteraksi sosial secara langsung atau nyata.

Dari hasil uji signifikan nilai korelasi antara indikator tolerance terhadap interaksi sosial adalah sebesar 0,5016082 dengan Pvalue 0,0002321 . Hal ini memperlihatkan bahwa indikator tolerance memiliki pengaruh terhadap interaksi sosial. Indikator ini menunjukkan bahwa para remaja terlibat aktif dalam bermain game sehingga membuat mereka bermain lebih dari dua jenis permainan akibatnya membutuhkan banyak waktu untuk bermain 
agar memperoleh perasaan bahagia sehingga para remaja mengabaikan pentingnya interaksi sosial dikehidupannya.

Antara indikator withdrawal symptoms terhadap interaksi sosial memiliki hasil uji signifikan nilai korelasi sebesar 0,4117372 dengan Pvalue 0,0080615. Sehingga memperlihatkan bahwa indikator withdrawal symptoms memiliki pengaruh yang nyata terhadap interaksi sosial pada remaja. Remaja yang begitu dominan melakukan aktivitas bermain game online merasa tidak menyenangkan bila waktu untuk bermain berkurang, akibatnya timbul rasa marah saat berkomunikasi dengan orang-orang yang berada di lingkungan sekitarnya.

Hasil uji signifikan nilai korelasi antara indikator Relapss terhadap interaksi sosial sebesar 0,4405295 dengan Pvalue 0,0067605. Sehingga indikator Relapss berpengaruh secara nyata terhadap interaksi sosial. Remaja yang memiliki keterikatan dalam bermain game online memiliki dampak negatif bukan hanya dalam berinteraksi sosial saja namun juga berdampak pada pendidikannya yaitu mereka sering melupakan bahkan mengabaikan tugastugas sekolahnya.

Pada hasil uji signifikan nilai korelasi terdapat indikator yang tidak memiliki hubungan signifikan terhadap interaksi sosial yaitu indikator conflict. Hasil uji signifikan nilai korelasi indikator conflict adalah sebesar 0,3954692 dengan Pvalue 0,7646528, hal ini menunjukkan bahwa tidak memiliki pengaruh yang nyata terhadap interaksi sosial. Para remaja yang menghabiskan waktu terlalu banyak untuk bermain game online membuat orang terdekatnya merasakan kekawatiran terhadap pergaulannya hingga membujuk remaja mengurangi waktu untuk bermain. Bagi remaja yang memahami kondisi ini, mereka akan menerima nasihat dan mengurangi waktu bermainnya.

\section{KESIMPULAN DAN SARAN}

Berdasarkan hasil analisis dan pembahasan pada Bab sebelumnya maka diperoleh kesimpulan bahwa terdapat hubungan yang signifikan antara kecanduan bermain game online terhadap interaksi sosial pada remaja, dengan nilai korelasi sebesar 0,8058964 dan Pvalue sebesar 0,0001994. Dimana remaja yang semakin kecanduan bermain game online akan mengalami penurunan terhadap interaksi sosialnya. Indikator interaksi sosial yang paling berpengaruh yaitu akomodasi, artinya jika intensitas bermain game online pada remaja tinggi akan membuat remaja mengalami kesulitan untuk menyesuaikan diri di kehidupannya.

Saran yang dapat diberikan berdasarkan hasil penelitian dan pembahasan Para remaja hendaknya mengurangi dan mengatur waktu untuk bermain game online. Remaja juga sebaiknya memanfaatkan waktu luang lebih banyak untuk berinteraksi sosial dengan temanteman, keluarga maupun masyarakat. Bagi orang tua diharapkan memperhatikan dan membatasi waktu bermain game online remaja agar remaja tidak kecanduan bermain game online. Untuk peneliti selanjutnya diharapkan mengembangkan penelitian dengan menambahkan indikator-indikator lain dalam variabel kecanduan game online dan interaksi sosial.

\section{DAFTAR PUSTAKA}

Dewi, Nita Puspita. 2014. Hubungan Antara Intensitas Bermain Game Online dengan Interaksi Sosial Pada Remaja. Jurnal Psikologi.

hhtp://eprints.ums.ac.id/31789/13/naskah_p ublikasi.pdf.

Griffith, M.D dan Davies, M.N.O. 2005. Does Video Game Addiction Exist?. In J. Goldstein \& Raessens (Eds.), Handbook of Computer Game Studies, pp.359-368. Boston- MIT Press

Kartono, Kartini. 2007. Psikologi Anak (Psikologi Perkembangan). Bandung: CV Mandar Maju.

Kusnadi, Edi dan Iskandar, Dadan. 2017. Peranan Tokoh Masyarakat dalam Membangun Partisipasi Kewargaan Pemuda Karang Taruna. Universitas Ahmad Dahlan. Yogyakarta

Soekanto, Soejono. 2012. Sosiologi Suatu Pengantar. Jakarta: Rajawali Pers.

Sugiyono. 2008. Metode Penelitian Kuantitatif Kualitatif dan $R \& D$. Bandung: Alfabeta.

Ulfa, Mimi. 2017. Pengaruh Kecanduan Game online Terhadap Perilaku Remaja. Jurnal Pendidikan. Vol.4 No 1. 